\title{
Open Access Publishing in Otorhinolaryngology: An Emerging Trend among Turkish Scientists?
}

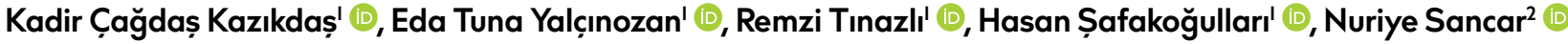 \\ 'Department of Otorhinolaryngology, Near East University School of Medicine, Nicosia, Cyprus \\ 2Department of Mathematics, Near East University School of Art and Sciences, Cyprus
}

ORCID IDs of the authors: K.C..K. 0000-000I-825I-2162; E.T.Y. 0000-000I-5392-5937; R.T. 0000-0003-3066-4804; H.Ș. 0000-000I-88964290; N.S. 0000-0002-4276-4653.

Cite this article as: Kazıkdaș KC̣, Yalçınozan ET, Tınazlı R, Șafakoğulları H, Sancar N. Open Access Publishing in Otorhinolaryngology: An Emerging Trend among Turkish Scientists? Cyprus J Med Sci 2018; 3(3): 164-7.

\section{BACKGROUND/AIMS}

Scientific medical publishing has undergone significant changes in the last few decades, enabled by advances in technology. Together with these technological innovations, the development of alternative methods has become inevitable. Most authors have had difficulty in making decision between open access and the traditional subscription-based journals. In this study we aimed to compare the changes in citation numbers of open access vs. subscription-based journals in Otorhinolaryngology publishing among Turkish authors and institutions.

\begin{abstract}
MATERIAL and METHODS
In this study we reviewed 28 Otorhinolaryngology (ORL) journals which have matched SCImago journal rank (SJR) values and included a total of 2,000 scientific papers published by Turkish authors between 2010 and 2015. All data extracted from SJR website and Google Scholar system.
\end{abstract}

\section{RESULTS}

There was statistically significant difference found between the subscription based (SB) and Open access (OA) according to the types of articles $(p=0.000)$. The difference between the mean total cite number per article of SB and OA journals is not statistically significant but close to level of significance $(p=0.061)$

\section{CONCLUSION}

When choosing between open access and subscription based journals to publish, it is important to consider the journal's visibility, the cost of publication. Open access publishing trend is on the rise among Turkish researchers, though they still mostly prefer the subscription based journals in otorhinolaryngology category.

Keywords: Subscription based, open access, otorhinolaryngology

\section{INTRODUCTION}

In the last few decades, scientific medical publishing has undergone significant changes. These changes have been possible because of advances in internet technology and worldwide communication opportunities. Apart from printed traditional journals, electronic publishing has become widespread (I). These technological innovations have made the development of alternative methods inevitable, when compared with the classical publishing where the costs were traditionally provided from the readers or the public resources. Indeed, anyone with internet access can reach open access (OA) publications online with no boundaries. Thus, OA means unrestricted and free access to all available scientific information. Throughout the years, the authors were concerned about the concept of OA publishing and its potential damage to the system. The main reason for such worries has been the perception that in case the OA journals collected publication fee from authors rather than from readers, those journals would tend to easily accept substandard articles since their income would be directly proportional to the number of articles published. Thus, most authors have had difficulty in making decision between OA and the traditional subscription-based (SB) journals. Indeed four main factors gain importance when selecting a journal: visibility, cost, prestige, and speed. 
Impact factor (IF) is one of the most important criteria used to evaluate the quality of scientific journals. Despite its widespread use in the scientific world, the IF provided by Institute for Scientific Information (ISI) has recently been discussed (2). The main points of the opposition are the deficiency of citation quality assessment, poor comparability between the different areas of interest of the journals, and mainly English content of the publications. Self-citations, which are defined as referring articles from the same journal, are also considered a problem of this ranking system.

Based on the comparisons made by Falagas et al. (3), the SClmago journal rank (SJR) index might be a good alternative to the well-established journal IF, basing upon its OA nature, larger source database, and assessment of the quality of citations. It is recommended that the authors should consider all of these indices rather than just IF alone while assessing the influence and importance of medical journals in their respective disciplines. In this study, we aimed to compare the changes between citation numbers of OA and SB journals from 2010 to 2015 to explore the changing trends in otorhinolaryngology (ORL) publishing among Turkish authors and institutions.

\section{MATERIAL and METHODS}

In this study, we reviewed 28 (I5 OA and I3 SB) ORL journals with matched SJR values (Table I), and included a total of 2000 scientific papers published by Turkish authors between 2010 and 2015. All data extracted from the SJR website have been used as input for statistical analysis. The features of the articles were classified according to their institution (university, training and research hospital, state or private hospital), type of article (original research, letter to editor, case report, or review article), and subdivisions of ORL (otology-neurotology, rhinology-facial plastics, head and neck surgery, or others). Total and mean number of cites attributed to these articles were scanned using Google Scholar. The articles originating outside Turkey were not included in this study.

\section{Statistical Analysis}

All statistical analyses were performed with the Statistical Package for the Social Sciences version 20.0 (IBM Corp.; Armonk, NY, USA) statistical package. Student's t test, Mann-Whitney U test, and Chi-square test were used for comparison of groups, where required. A p of less than 0.05 was chosen as statistically significant.

\section{RESULTS}

There was no statistically significant difference between the mean SJR values of matched OA and SB journals in 2015 list $(p=0.105)$ (Table I). Among those 28 journals, the "Journal of Craniofacial Surgery", an SB journal, having an SJR index of 0.443 in 2015, was the host of the largest number of articles published by Turkish authors between years 2010 and $2015(n=805)$. It was followed by "European Archives of ORL" ( $n=266)$, "International Journal of Pediatric Otorhinolaryngology" ( $n=183)$, and "The Journal of International Advanced Otology" $(n=180)$.

This study included 2000 scientific papers (1604 in SB journals and 396 in OA) published by Turkish authors between 2010 and 2015. According to their institutions, 1280 of these articles originated from university hospitals, and 559 originated from training and research hospitals. There was no statistically significant difference between the SB and OA journals when compared with origin of the articles $(p=0.197)$ (Table 2).

Statistically significant difference was found between the SB and OA journals according to the types of articles $(p<0.001)$.

TABLE I. List of matched subscription based (SB) and Open Access (OA) journals included in this study

\section{Subscription-based journals and SJR values (2015)}

- Journal of Oral and Maxillofacial Surgery (0.938)

- European Archives of ORL (0.863)

- Current Opinion in Otorhinolaryngology and Head $\delta$ Neck Surgery (0.846)

- Journal of Otolaryngology Head and Neck Surgery (0.84I)

- Clinical Otolaryngology (0.779)

- International Journal of Pediatric Otorhinolaryngology (0.707)

- Cochlear Implants International (0.619)

- Journal of Vestibular Research (0.610)

- American Journal of Otolaryngology-Head and Neck Medicine and Surgery (0.586)

- Journal of Craniofacial Surgery (0.478)

- Journal of Laryngology $\delta$ Otology (0.464)

- Oral and Maxillofacial Surgery Clinics of North America (0.401)

- Indian Journal of Otolaryngology and Head d Neck Surgery (0.282)

\section{Open access journals and SJR values (2015)}

- Acta Otorhinolaryngologica Italica (0.877)

- BMC Ear Nose Throat Disorder (0.780)

- European Annals of Otorhinolaryngology Head and Neck Diseases (0.650)

- Noise $\delta$ Health (0.563)

- Clinical and Experimental Otorhinolaryngology (0.552)

- Journal of Orald Maxillofacial Pathology (0.418)

- Head and Neck Oncology (0.452)

- Brazilian Journal of Otolaryngology (0.40I)

- International Tinnitus Journal (0.374)

- Iranian Journal of Otorhinolaryngology (0.293)

- B-ENT (0.24I)

- Indian Journal of Otology (0.232)

- ENT Journal (0.23I)

- International Archives of Otorhinolaryngology (0.168)

- Journal of International Advanced Otology (0.158)

*Mann-Whitney U test. $\mathrm{p}=0.105$

SJR: SCImago journal rank 
TABLE 2. Total number of published articles according to their institutions and type of the subscription

Type of the subscription

Institution

\begin{tabular}{|c|c|c|c|c|c|}
\hline & University & Training and research hospital & State hospital & Private hospital & Total \\
\hline SB & $1029(\% 51.45)$ & $437(\% 21.85)$ & $96(\% 4.8)$ & $42(\% 2.1)$ & $1604(\% 80.2)$ \\
\hline OA & $251(\% 12.5)$ & $122(\% 6.1)$ & $15(\% 0.75)$ & $8(\% 0.4)$ & $396(\% 19.8)$ \\
\hline
\end{tabular}

TABLE 3. Total number of published articles according to their type of article and type of the subscription

\begin{tabular}{|c|c|c|c|c|c|}
\hline \multirow[t]{2}{*}{ Type of the subscription } & \multicolumn{4}{|c|}{ Type of article } & \multirow[b]{2}{*}{ Total } \\
\hline & Original research & Letter to editor & Case report & Review article & \\
\hline SB & $1051(\% 52.55)$ & I5I (\%7.55) & $383(\% 19.5)$ & $19(\% 0.95)$ & $1604(\% 80.2)$ \\
\hline Total & $1315(\% 65.75)$ & $155(\% 7.75)$ & $508(\% 25.5)$ & $22(\% \mathrm{l} . \mathrm{I})$ & 2000 \\
\hline
\end{tabular}

TABLE 4. Total number of published articles according to their subdivisions of ORL-HNS and type of the subscription

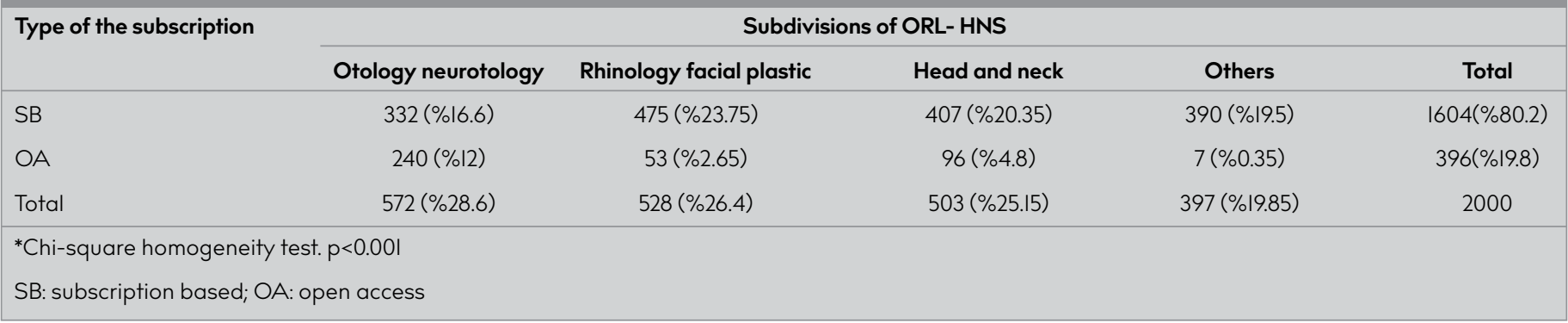

TABLE 5. Total number of published articles according to their institutions and type of article

Institution

$\begin{array}{lcc} & \text { Original research } & \text { Letter to editor } \\ \text { University } & 822(\% 41.1) & 98(\% 4.9) \\ \text { Training and research hospital } & 379(\% 18.95) & 42(\% 2.1) \\ \text { State hospital } & 79(\% 3.95) & 9(\% 0.45) \\ \text { Private hospital } & 35(\% 1.75) & 6(\% 0.3) \\ \text { Total } & 1315(\% 65.75) & 155(\% 7.75)\end{array}$

${ }^{*}$ Chi-square homogeneity test. $p=0.197$

\section{Type of article}

$\begin{array}{ccc}\text { Case study } & \text { Review article } & \text { Total } \\ 339(\% 16.95) & 21(\% 1.05) & 1280(\% 64) \\ 138(\% 6.9) & 0 & 559(\% 27.95) \\ 23(\% 1.15) & 0 & 111(\% 5.55) \\ 8(\% 0.4) & 1(\% 0.05) & 50(\% 2.5) \\ 508(\% 25.4) & 22(\% .1) & 2000\end{array}$

tic $(n=528)$. The SB and OA journals have statistically significant difference according to their subdivisions $(p<0.001$ ) (Table 4)

according to the type of subscription

\begin{tabular}{|lcc|}
\hline Type of the subscription & Mean of total cite & Standard error \\
\hline Subscription based & 4.28 & \pm 1.370 \\
Open access & 5.76 & \pm 0.199 \\
\hline *Student's $t$ test. $p=0.061$ & & \\
\hline
\end{tabular}

Original research articles were the most frequently published type in the SB journals ( $n=105 \mid$ ) (Table 3 ).

Among the ORL subdivisions, the most common topics were otology and neurotology $(n=572)$ and rhinology and facial plas-
The types of articles were classified according to the origin of their institutions. The most frequent one was research articles from university hospitals among all institutions $(n=822)$ (Table 5). Student's t test revealed that the difference between the mean total cite number per article of SB and OA journals is not statistically significant, but close to level of significance $(p=0.061)$ (Table 6).

\section{DISCUSSION}

The SJR indicator is a measure of the scientific impact of medical journals. It explains the number of citations a journal receives, 
and the value or dignity of the journals in which such citations come from. It is a numeric value that represents the average number of quotes received during the year selected in a document published in a medical journal over the last three years. The higher the SJR values, the higher is the prestige of the magazine (I). Different types of OA journals with various publishing modalities such as green, gold, and hybrid OA are currently in use. "Gold" OA is an example with unlimited instant access to all articles on the journals' website. With "Green" OA, researchers can reach the articles via the repositories of the institutions. In terms of "Delayed" OA, accessibility can be carried out after an embargo period. After a processing charge paid by the author in an SB journal, the article will be free to public access known as "Hybrid" OA (4). Thus, OA is not only a single unambiguous term, but is rather a set of possible strategies to distribute unrestricted scientific information accessible to all.

In the new era of constantly expanding internet technology, there are a large number of platforms, including social media sites and blogs, which can be accessed for free by anyone with an internet connection and a smartphone. Unlike traditional $\mathrm{SB}$ journals that require high registration fees from academic researchers to access journal content, the OA journals encourage authors to publish their findings online almost free of charge. This publishing modality plays an important role in the visibility and potential citations of an article required for the academic prestige. The "h-index", a new indicator proposed by Jorge E. Hirsch in 2005, is widely used today to evaluate scientists' research performance, rather than just the number of articles they produce. It measures the productivity of the scientist and the quality of that productivity altogether. To have a high h-index, it is necessary to publish significant number of articles. Each of these printed articles should have high citation numbers. At this stage, easy accessibility and high visibility of a printed article play a major role in achieving the desired high number of citations. Although the OA journals fulfill these criteria appropriately, they have been criticized for having a lower impact factor and poor peer review quality. However, the results of this study show that these determinations have begun to change with an increasing number of citations that the OA journals receive over the recent years in scientific indices. Although our quantitative findings were in accordance with the dominancy of the SB journals, the citation analyses revealed that as of 2015, the OA journals started to receive more citations than their SB equivalents did. This novel trend is on the rise among Turkish researchers. However, another interesting result of this study shows that the Turkish authors still prefer the SB journals for their academic visibility and prestige. The number of medical schools in Turkey ranked 8th in the 2014 list of top twenty world universities. This leads to a fierce competition for academic positions. Thus, the scientific publication rates are likely to increase even further $(5,6)$.

When choosing between the OA and SB journals to get the content published, it is important to consider the journal's visibility, the cost of publication, the IF or SJR of the journal, and the speed of publication. To the best of our knowledge, this is the first study in the English literature to compare the OA and SB journals in the ORL category, demonstrating the novel changing trends in medical publishing among Turkish scientists between 2010 and 20I5. This type of scientific work on ORL can easily be replicated and applied to any other medical field or specialty. The current trends in medical publishing can be explored more specifically.

Ethics Committee Approval: N/A.

Informed Consent: N/A.

Peer-review: Externally peer-reviewed.

Author contributions: Concept - K.C..K; Design - K.C..K, E.T.Y., R.T; Supervision - K.C..K.; Data Collection and/or Processing - E.T.Y., R.T., H.S., N.S.; Analysis and/or Interpretation - R.T., H.S., N.S.; Literature Search - K.C..K., R.T., E.T.Y; Writing - K.C..K., E.T.Y., R.T.; Critical Reviews - K.CC.K., H.S., N.S.

Conflict of Interest: The authors have no conflicts of interest to declare.

Financial Disclosure: The authors declared that this study has received no financial support.

\section{REFERENCES}

I. Falagas ME, Kouranos VD, Arencibia-Jorge R, Karageorgopoulos DE. Quality Assessment of Studies Published in Open Access and Subscription Journals: Results of a Systematic Evaluation. FASEB J 2008; 22: 2623-8. [CrossRef]

2. Björk BC, Solomon D. Open access versus subscription journals: a comparison of scientific impact. BMC Medicine 2012; 10: 73. [CrossRef]

3. Siebelt $M$, Siebelt $T$, Pilot $P$, Bloem RM, Bhandari M, Poolman RW. Citation analysis of orthopaedic literature; 18 major orthopaedic journals compared for Impact Factor and SCImago. BMC Musculoskelet Disord 20I0; II: 4. [CrossRef]

4. Piwowar H, Priem J, Larivière V, Alperin JP, Matthias L, Norlander Bet al. The state of OA: a large-scale analysis of the prevalence and impact of Open Access articles. PeerJ 2018; 6: e4375. [CrossRef]

5. Duvivier RJ, Boulet JR, Opalek A, Van Zanten M, Norcini J. Overview of the world's medical schools: an update. Med Educ 20l4; 48: 860-9. [CrossRef]

6. Erdağ TK, Durmușoğlu M, Özay H, Sönmez F, Doğan E. Turkey's place in Europe in respect of pediatric otorhinolaryngology publications in scope of Science Citation Index. Kulak Burun Bogaz Ihtis Derg 2015; 25: 163-9. [CrossRef] 